\title{
Current Aspects on Oral Squamous Cell Carcinoma
}

\author{
Anastasios K. Markopoulos* \\ Oral Medicine/Pathology Aristotle University of Thessaloniki, Greece
}

\begin{abstract}
Oral squamous cell carcinoma is the most common malignant epithelial neoplasm affecting the oral cavity. This article overviews the essential points of oral squamous cell carcinoma, highlighting its risk and genomic factors, the potential malignant disorders and the therapeutic approaches. It also emphasizes the importance of the early diagnosis.
\end{abstract}

Keywords: Oral squamous cell carcinoma, overview.

\section{INTRODUCTION}

Worldwide, oral cancer accounts for $2 \%-4 \%$ of all cancer cases. In some regions, the prevalence of oral cancer is higher, reaching the $10 \%$ of all cancers in Pakistan, and around $45 \%$ in India [1,2]. In 2004-2009 over 300,000 new cases of oral and oropharyngeal cancer were diagnosed worldwide. During the same time period, over 7,000 affected individuals died of these cancers [3].

Oral cancer includes a group of neoplasms affecting any region of the oral cavity, pharyngeal regions and salivary glands. However, this term tends to be used interchangeably with oral squamous cell carcinoma (OSCC), which represents the most frequent of all oral neoplasms. It is estimated that more of $90 \%$ of all oral neoplasms are OSCC [4].

Despite the advances of therapeutic approaches, percentages of morbidity and mortality of OSCC have not improved significantly during the last 30 years. Percentages of morbidity and mortality in males are 6.6/100,000 and 3.1/100,000 respectively, while in females the same percentages are 2.9/100,000 and 1.4/100,000 [5]. Additionally, the incidence of OSCC is increasing among young white individuals age 18 to 44 years, particularly among white women [6]. The percentage of 5-year survival for patients with OSCC varies from $40-50 \%$. Regardless of the easy access of oral cavity for clinical examination, OSCC is usually diagnosed in advanced stages. Most common reasons are the initial wrong diagnosis and the ignorance from the patient or from the attending physician [7].

\section{CLINICAL FEATURES}

One of the real dangers of this neoplasm, is that in its early stages, it can go unnoticed. Usually at the initial stages it is painless but may develop a burning sensation or pain when it is advanced. Common sites for OSCC to develop are on the tongue, lips and floor of the mouth. Some OSCCs arise in apparently normal mucosa, but others are preceded

*Address correspondence to this author at the Aristotle University, Dept. of Oral Medicine/Pathology, University Campus, 54124 Thessaloniki, Greece; Tel: +30 2310 999523; Fax: +30 2319 999532;

E-mail: anmark@dent.auth.gr

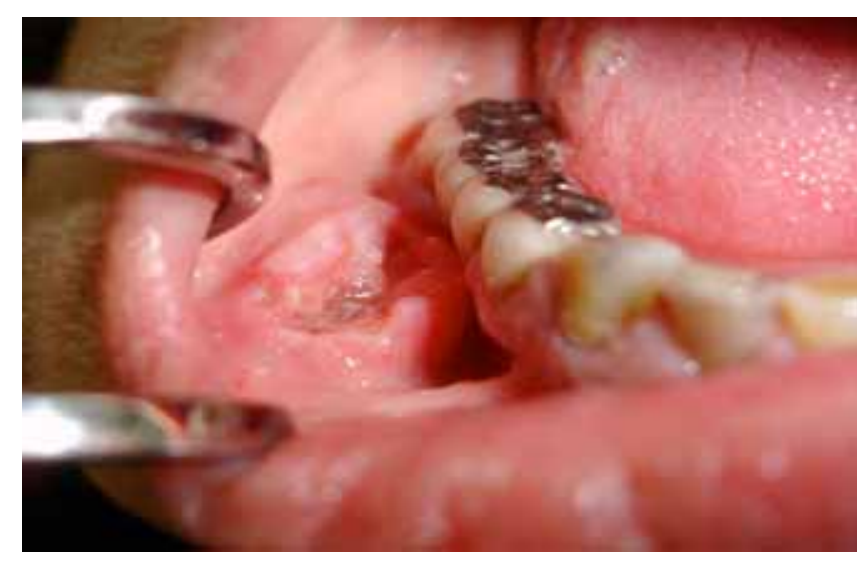

Fig. (1). OSCC of the vestibule with raised exophytic margins.

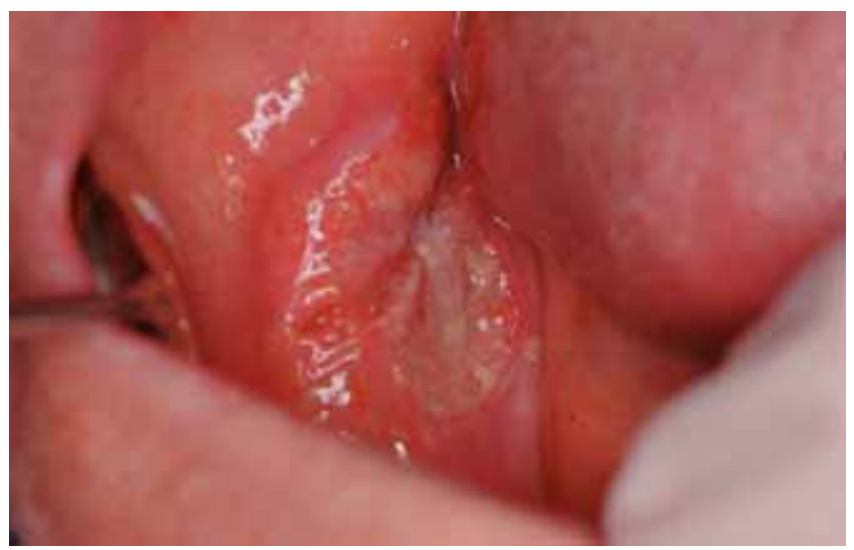

Fig. (2). OSCC of the buccal mucosa presenting as an asymptomatic ulcer.

by clinically obvious premalignant lesions, especially erythroplakia and leukoplakia. Usually, OSCC presents as an ulcer with fissuring or raised exophytic margins (Fig. 1). It may also present as a lump (Fig. 2), as a red lesion (erythroplakia), as a white (Fig. 3) or mixed white and red lesion, as a non-healing extraction socket or as a cervical lymph node enlargement, characterized by hardness or fixation. OSCC should be considered where any of these features persist for more than two weeks. 


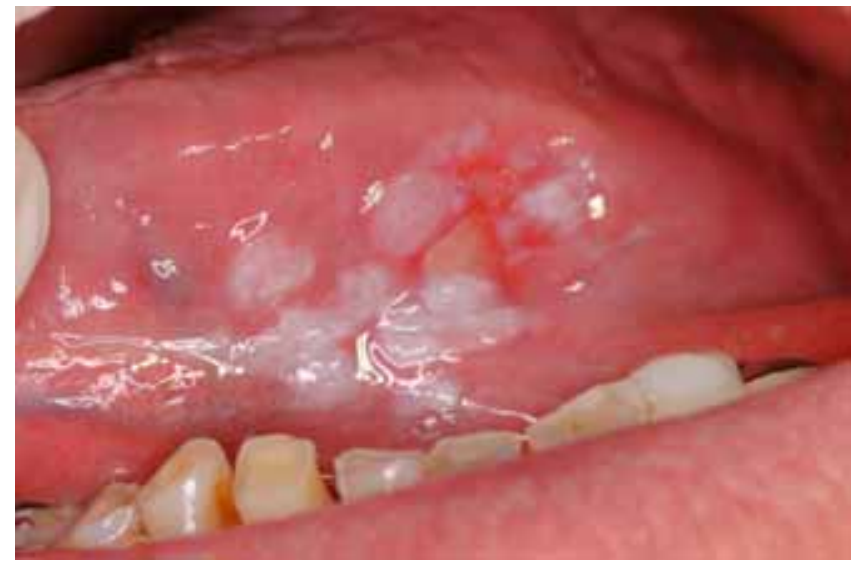

Fig. (3). Leukoplakia of the lateral surface of the tongue undergoing malignant transformation.

\section{RISK FACTORS}

The greatest risk factor for oral cancer in the western world is the use of tobacco and alcohol [8-12]. Although the risk factors are independent, their action seems to be combined. Tobacco smoking is associated with $75 \%$ of all cases of oral cancer. Tobacco smoking carries a six-fold risk of developing oral cancer compared to not smoking. Oral cancer is also six times more likely to develop in alcohol drinkers than in non-drinkers. The combination of tobacco and alcohol use poses a fifteen-fold risk of oral cancer for users compared to non-users [13].

While tobacco and alcohol use are traditionally the greatest risk factors, it is important to consider other known risk factors, such as betel quid chewing, in certain ethnic populations. Betel quid chewing is popular in Indian and Taiwanese populations and is associated with a significantly increased risk of oral cancer [14-16]. Areca nut, narcotics and cannabis use has also been found to be a risk factor for oral cancer [17].

OSCC is most common in older males, in lower socioeconomic groups and in ethnic minority groups.

Other factors also play a role. These include:

- An impaired ability to repair DNA damaged by mutagens

- An impaired ability to metabolize carcinogens

- Deficiencies of vitamins A, E or C or trace elements

- Immune defects.

The inadequate immune response may predispose to cancer development. The most common oral malignancy in individuals with HIV infection is Kaposi's sarcoma. There is a high prevalence in patients with B cell Hodgkin lymphoma. There is an increased risk of developing OSCC in HIV infected patients and patients submitted to organ transplantations and those who are under immunosuppressive therapy $[5,18]$.

\section{VIRAL INFECTIONS}

\section{Human Papilloma Virus (HPV)}

More than 100 types of HPV have been identified and are referred as viruses of low or high danger according to their oncogenetic potential. The predominant viral type, in most studies, was HPV16. HPV was more frequently detected in OSCCs of the oropharynx and tonsil than at other head and neck sites. Research on the participation of HPV in oral carcinogenesis has conflicting results. The percentage of the reported infected neoplastic cells varies from $0-90 \%$.Several research groups proposed that HPV is implicated in the initial stages of carcinogenesis, while others have suggested a short-term ("hit and run") role of HPV. It is believed that viral protein E6 binds to p53 causing its breakdown, while E7 reacts with retinoblastoma protein ( $\mathrm{pRb})$, a tumor suppressor protein, inhibiting its function. The functional deregulation of these oncosuppressive key molecules results in an incontrollable cellular proliferation and to disturbances of apoptosis, leading to oral cancer. It is currently believed that HPV infection of oral mucosal cells per se is not enough for malignant transformation unless cells are exposed to chemical carcinogens, such as benzopyrene [19-23].

\section{Epstein-Barr Virus}

Epstein-Barr virus is known to be the infective agent in infectious mononucleosis. While its contribution to malignant transformation of B cells is well documented the participation in pathogenesis of OSCC remains unclear. Some investigators proposed that the dominant oncoprotein of the latent phase (LMP-1) is expressed in oral epithelial malignant cells $[23,24]$.

\section{Hepatitis C Virus (HCV)}

The prevalence of oral squamous cell carcinoma is higher in HCV infected patients. In a Japanese study, it has been shown that HCV infection was strongly associated with the occurrence of multiple primary carcinomas as well as primary OSCC [25].

\section{POTENTIALLY MALIGNANT DISORDERS}

In a recently held WHO workshop it was recommended that the distinction between potentially malignant lesions and potentially malignant conditions should be abandoned and rather to use the term potentially malignant disorders instead [26].

Some precancerous disorders can progress to OSCC. These are the following:

- Erythroplakia

- Leukoplakias, particularly:

-Erythroleukoplakia (nodular or verrucous)

-Proliferative verrucous leukoplakia

- Actinic cheilitis

- Lichen planus (mainly the erosive and atrophic type)

- Sideropenic dysphagia (Plummer-Vinson syndrome)

- Submucous fibrosis

- Dyskeratosis congenita

- Discoid lupus erythematosus

\section{MOLECULAR PATHOGENESIS OF OSCC}

Several studies have been devoted to the significance of heredity in oral carcinogenesis. The relative danger of the 
disease development in first degree relatives of patients with oral cancer varies from 1.1-3.8 odds ratios [27]. Several genes are implicated in genetic predisposition of oral cancer. Gene polymorphisms participating in the metabolism of xenobiotic factors, such as cytochrome P450 1A1 (CYPIA 1) and glutathione S-transferase mu 1 (GSTM1) are blamed for the increase of relative danger in the carriers $[28,29]$. Individuals with alcohol dehydrogenase 3 genotype are prone to the development of oropharyngeal cancers $[30,31]$.

However, the relation of oral cancer with an autosomal dominant type of heredity has been rarely recorded, mainly in patients with Fanconi's anemia.

OSCC arises as a consequence of multiple molecular events that develop from the combined effects of an individual's genetic predisposition and exposure to environmental carcinogens [32], such as, tobacco, alcohol, chemical carcinogens, ultraviolet or ionizing radiation and microorganisms [33-35]. Chronic exposure to carcinogens may damage individual genes as well as larger portions of the genetic material, such as chromosomes. Genetic damages may activate mutations or amplification of oncogenes that promote cell survival and proliferation. Mutations include DNA general hypomethylation, hyper- or hypomethylation of certain genes such as cyclin D, and alterations of chromatin $[36,37]$. Oncogenes are broadly categorized as follows: (i) growth factors or growth factor receptors (hst-1, int-2, EGFR/erbB, c-erbB-2/Her-2, sis), (ii) transcription factors (myc, fos, jun, c-myc), (iii) intracellular signal transducers (ras, raf, stat-3); (iv) inhibitory factors of apoptosis (bcl-2, bax) and (v) cell-cycle regulators (cyclin D1) [38]. Genetic damages may also inactivate tumor suppressor genes involved in the inhibition of cell proliferation. All these events may lead to cell dysregulation to the extent that growth becomes autonomous and invasive mechanisms develop.

As OSCC grows and invades, new blood vessel formation occurs. This angiogenesis is an essential part of tumor formation [39].

Field cancerization is a theory of oral carcinogenesis. According to this theory since the oral epithelium is exposed to carcinogenic factors, the entire area is at increased risk for the development of malignant lesions from the accumulation of genetic alterations of oncogenes and tumor suppressor genes [40].

In cancerization field, multiple oral cancers may develop from independent cell clones. This hypothesis has been supported by data from chromosome $\mathrm{X}$ inactivation studies, microsatellite analysis, and p53 mutational analysis [41]. However, more recent genetic studies suggested that multiple cancers can be clonally related and derived from expansion of an original clone [42]. These results gave rise to a modification of cancerization field theory, the patch field carcinoma model [43]. According to this model, a stem cell located in the oral epithelium acquires a genetic alteration and generates daughter cells, all of which share the genetic alteration. This patch of cells expands to a size of several centimeters to the surrounding oral mucosa and macroscopically is often undetectable. In some instances it may appear with distinct morphological characteristics, like leukoplakia or erythroplakia.

\section{STAGING OF OSCC}

Staging of OSCC is performed using the TNM system. cTNM is the stage given after the clinical examination of the patient, while pTNM is the stage after the histopathological examination of the surgical specimen. However, this traditional way of staging is often inadequate. Evaluation of other features of the neoplasms, such as degree of differentiation, type of infiltration and degree of recurrence [44] facilitate the exact diagnosis and permit the selection of the appropriate therapeutical approach.

\section{THERAPEUTIC APPROACHES AND PROGNOSIS}

Despite advances in surgery and radiotherapy, which remain the standard treatment options, the mortality rate has remained largely unchanged for decades, with a 5-year survival rate of around 50\% [45]. In the primary (I and II) stages the treatment of choice is surgery and/or radiotherapy, which usually result in permanent cure. Combination of surgery, radiotherapy or chemotherapy is used for the treatment of the $3^{\text {rd }}$ or $4^{\text {th }}$ stage of OSCC. Oral care is especially important when radiotherapy is to be given, since there is a liability particularly to mucositis, xerostomia and osteonecrosis.

It is generally accepted that prognosis is best in early OSCC, especially those that are well-differentiated and not metastasized: unfortunately, most OSCC are diagnosed at a late stage

of the disease. The prognosis of OSCC varies on a number of factors that are related to the tumor, to the treatment, and to the patient [46]. However, five year survival rates in the advanced stages do not exceed $12 \%$ of the cases. Most patients with advanced OSCC usually die within the first 30 months of their disease $[47,48]$.

Metastases from OSCC, when present, will occur in cervical lymph nodes in almost $80 \%$ of patients. Cervical lymphadenectomy (radical neck dissection) is traditionally applied in these cases [49]. More recently, selective neck dissection has been developed in order to reduce the morbidity of radical neck dissection [50].

Efforts to increase the efficacy of radiotherapy, especially in local advanced disease, include, altered fractionated radiotherapy or concomitant chemo-radiotherapy (CT-RT) [51].

As for chemotherapy, cisplatin-based chemoradiation remains the standard for locoregionally advanced head and neck SCC [52].

Currently, targeted molecular therapy, like therapy with monoclonal antibodies and gene therapy, has been applied to oral cancer patients. This treatment modality has limited or nonexistent side effects on normal cells of the body, unlike surgery, chemotherapy, and radiotherapy. Targeted molecular therapy can also act as a complement to other existing cancer therapies and has been mainly focused on four molecules; epidermal growth factor receptor (EGFR), cyclooxygenase-2 (COX-2), peroxisome proliferator-activated receptor $\gamma$ (PPAR $\gamma$ ), and progesterone receptor. These molecules are associated with the proliferation and the differentiation of OSCC [53]. 
Finally, early diagnosis remains the key element for the sufficient therapy of OSCC. Clinicians should be aware that single ulcers, tumors, red or white plaques, particularly if any of these are persisting for more than two weeks, may be manifestations of malignancy. In these cases a biopsy from the suspicious lesion is needed. Finally, new emerging technologies are developing and targeting to early diagnosis of OSCC through molecular analysis of cytologic smears or saliva samples [54].

\section{CONFLICT OF INTEREST}

The author confirms that this article content has no conflicts of interest.

\section{ACKNOWLEDGEMENT}

Declared none.

\section{REFERENCES}

[1] Williams HK. Molecular pathogenesis of oral squamous carcinoma. Mol Pathol 2000; 53: 165-72.

[2] Siddiqui IA, Farooq MU, Siddiqui RA, Rafi SMT. Role of toluidine blue in early detection of oral cancer. Pak J Med Sci 2006; 22:184-7.

[3] Sharma P, Saxena S, Aggarwal P. Trends in the epidemiology of oral squamous cell carcinoma in Western UP: an institutional study. Ind J Dent Res 2010; 21: 316-9.

[4] Choi S, Myers JN. Molecular pathogenesis of oral squamous cell carcinoma: implications for therapy. J Dent Res 2008; 87: 14-32.

[5] Mehrotra R, Yadav S. Oral squamous cell carcinoma: etiology, pathogenesis and prognostic value of genomic alterations. Indian $\mathbf{J}$ Cancer 2006; 43: 60-6.

[6] Patel SC, Carpenter WR, Tyree S, et al. Increasing incidence of oral tongue squamous cell carcinoma in young white women, age 18 to 44 years. J Clin Oncol 2011; 29(11): 1488-94.

[7] Scott SE, Grunfeld EA, Main J, McGurk M. Patient delay in oral cancer: a qualitative study of patients' experiences. Psychooncology 2006; 15: 474-85.

[8] Chole RH, Patil RN, Basak A, Palandurkar K, Bhowate R. Estimation of serum malondialdehyde in oral cancer and precancer and its association with healthy individuals, gender, alcohol, and tobacco abuse. J Cancer Res Ther 2010; 6: 487-91.

[9] de FreitasCordeiro-Silva M, Oliveira ZF, de Podestá JR, Gouvea SA, Von Zeidler SV, Louro ID. Methylation analysis of cancerrelated genes in non-neoplastic cells from patients with oral squamous cell carcinoma. Mol Biol Rep 2011; 38(8): 5435-41.

[10] Marichalar-Mendia X, Acha-Sagredo A, Rodriguez-Tojo MJ, et al. Alcohol-dehydrogenase (ADH1B) Arg48His polymorphism in Basque country patients with oral and laryngeal cancer: preliminary study. Anticancer Res 2011;31: 677-80.

[11] Warnakulasuriya S, Sutherland G, Scully C. Tobacco, oral cancer and treatment of dependence. Oral Oncol 2005; 41: 244-60.

[12] Zygogianni AG, Kyrgias G, Karakitsos P, et al. Oral squamous cell cancer: early detectionand the role of alcohol and smoking. Head Neck Oncol 2011; 3: 2.

[13] Ogden GR. Alcohol and oral cancer. Alcohol 2005; 35:169-73.

[14] Su CC, Yang HF, Huang SJ, LianIeB. Distinctive features of oral cancerin Changhua County: high incidence, buccal mucosa preponderance, and a close relation to betel quid chewing habit. $\mathrm{J}$ Formos Med Assoc 2007; 106: 225-33.

[15] Ko YC, Huang YL, Lee CH, Chen MJ, Lin LM, Tsai CC. Betel quid chewing, cigarette smoking and alcohol consumption related to oral cancer in Taiwan. J Oral Pathol Med 1995; 24(10): 450-3.

[16] Subapriya R, Thangavelu A, Mathavan B, Ramachandran CR, Nagini S. Assessment of risk factors for oral squamous cell carcinoma in Chidambaram,Southern India: a case-control study. Eur J Cancer Prev 2007; 16: 251-6.

[17] Thavarajah R, Rao A, Raman U, Rajasekaran ST, Joshua ERH, Kannan R. Oral lesions of 500 habitual psychoactive substance users in Chennai, India. Arch Oral Biol 2006; 51: 512-9.
[18] Kulkarni DP, Wadia PP, Pradhan TN, Pathak AK, Chiplunkar SV. Mechanisms involved in the down-regulation of TCR zeta chain in tumor versus peripheral blood of oral cancer patients. Int J Cancer 2009; 124: 1605-13.

[19] Angiero F, Gatta LB, Seramondi R, et al. Frequency and role of $\mathrm{HPV}$ in the progression of epithelial dysplasia to oral cancer. Anticancer Res 2010; 30: 3435-40.

[20] Nuovo GJ. In situ detection of human papillomavirus DNA after PCR-amplification. Methods Mol Biol 2011; 688: 35-46.

[21] Scully C, Felix DH. Oral medicine: update for the dental practitioner. Oral cancer. British Dent J 2006; 200: 13-7.

[22] Syrjänen $\mathrm{S}$. The role of human papillomavirus infection in head and neck cancers. Ann Oncol 2010; 21(Suppl 7): vii 243-vii 245.

[23] Jalouli J, Ibrahim SO, Mehrotra R, et al. Prevalence of viral (HPV, EBV, HSV) infections in oral submucous fibrosis and oral cancer from India. Acta Otolaryngol 2010; 130(11): 1306-11.

[24] Gonzalez-Molez MA, Gutierrez J, Rodriguez MJ, Ruiz-Avila I, Rodriguez-Archilla A. Epstein-Barr virus latent membrane protein1 (LMP-1) expression in oral squamous cell carcinoma. Laryngoscope 2002; 112: 482-7.

[25] Nagao Y, Sata M. High incidence of multiple primary carcinomas in HCV-infected patients with oral squamous cell carcinoma. Med Sci Monit 2009; 15: CR453-9.

[26] van der Waal I. Potentially malignant disorders of the oral and oropharyngeal mucosa; terminology, classification and present concepts of management. Oral Oncol 2009; 45: 317-23.

[27] Garavello W, Foschi R, Talamini R, et al. Family history and the risk of oral and pharyngeal cancer. Int J Cancer 2008; 122: 182731.

[28] Sreelekha TT, Ramadas K, Pandey M, Thomas G, Nalinakumari KR, Pillai MR. Genetic polymorphism of CYPIA1, GSTM1 and GSTT1 genes in Indian oral cancer. Oral Oncol 2001; 37: 593-8.

[29] Li H, Chen XL, Li HQ. Polymorphism of CYPIA1 and GSTM1 genes associated with susceptibility of gastric cancer in Shandong Province of China. World J Gastroenterol 2005; 11: 5757-62.

[30] Harty LC, Caporaso NE, Hayes RB, et al. Alcohol dehydrogenase 3 genotype and risk of oral cavity and pharyngeal cancers. J Natl Cancer Inst 1997; 89: 1698-705.

[31] Solomon PR, Selvam GS, Shanmugam G. Polymorphism in ADH and MTHFR genes in oral squamous cell carcinoma of Indians. Oral Dis 2008; 14: 633-9.

[32] Califano J, van der Riet P, Westra W, et al. Genetic progression model for head and neck cancer: implications for field cancerization. Cancer Res 1996; 56: 2488-92.

[33] Markopoulos A, Albanidou-Farmaki E, Kayavis I. Actinic cheilitis: clinical and pathologic characteristics in 65 cases. Oral Diseases 2004; 10: 212-6.

[34] Preston DL, Ron E, Tokuoka S, et al. Solid cancer incidence in atomic bomb survivors: 1958-1998. Radiat Res 2007; 168: 1-64.

[35] O'Grady JF, Reade PC. Candida albicans as a promoter of oral mucosal neoplasia. Carcinogenesis 1992; 13: 783-6.

[36] Huang M, Spitz MR, Gu J, et al. Cyclin D1 gene polymorphism is a risk factor for oral premalignant lesions. Carcinogenesis 2006; 27: 2034-7.

[37] Díez-Pérez R, Campo-Trapero J, Cano-Sánchez J, et al. Methylation in oral cancer and pre-cancerous lesions (Review).Oncol Rep 2011; 25(5): 1203-9.

[38] Sidransky D. Molecular genetics of head and neck cancer. Curr Opin Oncol 1995; 7: 229-33.

[39] Michailidou E, Markopoulos AK, Antoniades DZ. Mast cells and angiogenesis in oral malignant and premalignant lesions. Open Dent J 2008; 2: 120-6.

[40] Slaughter DP, Southwick HW, Smejkal W. Field cancerization in oral stratified squamous epithelium: clinical implication of multicentric origin. Cancer 1953; 6: 963-8.

[41] Bedi GC, Westra WH, Gabrielson E, Koch W, Sidransky D. Multiple head and neck tumors: evidence for a common clonal origin. Cancer Res 1996; 56: 2484-7.

[42] Braakhuis BJ, Tabor MP, Kummer JA, Leemans R, Brakenhoff RH. A genetic explanation of Slaughter's concept of field cancerization: evidence and clinical implications. Cancer Res 2003; 63:1727-30.

[43] Braakhuis BJ, Leemans CR, Brakenhoff RH. A genetic progression model of oral cancer: current evidence and clinical implications. J Oral Pathol Med 2004; 33: 317-22. 
[44] Lacy PD, Spitznagel EL, Piccirillo JF. Development of a new staging system for recurrent oral cavity and oropharyngeal squamous cell carcinoma. Cancer 1999; 86; 1387- 95.

[45] Marsh D, Suchak K, Moutasim KA, et al. Stromal features are predictive of disease mortality in oral cancer patients. J Pathol 2011; 223: 470-81.

[46] de Araújo RF, Barboza Jr CA, Clebis NK, de Moura SA, Lopes Costa Ade L. Prognostic significance of the anatomical location and TNM clinical classification in oral squamous cell carcinoma. Med Oral Pathol Oral Cir Bucal 2008; 13: E344-7.

[47] Hill BT, Price LA. Lack of survival advantage in patients with advanced squamous cell carcinomas of the oral cavity receiving neoadjuvant chemotherapy prior to local therapy, despite achieving an initial high clinical complete remission rate. Am J Clin Oncol 1994; 17: 1-5.

[48] Zini A, Czerninski R, Sgan-Cohen HD.Oral cancer over four decades: epidemiology, trends, histology, and survival by anatomical sites. J Oral Pathol Med 2010; 39: 299-305.
[49] Shah JP, Gil Z. Current concepts in management of oral cancer: surgery. Oral Oncol 2009; 45: 394-401.

[50] Pagedar NA, Gilbert RW. Selective neck dissection: a review of the evidence. Oral Oncol 2009; 45: 416-20.

[51] Mazeron R, Tao Y, Lusinchi A, Bourhis J. Current concepts in management in head and neck cancer; radiotherapy. Oral Oncol 2009; 45: 402-8.

[52] Specenier PM, Vermorken JB. Current concepts for the management of head and neck cancer: Chemotherapy. Oral Oncol 2009; 45: 409-15.

[53] Hamakawa H, Nakashiro K, Sumida T, et al. Basic evidence of molecular targeted therapy for oral cancer and salivary gland cancer. Head Neck 2008; 30: 800-9.

[54] Markopoulos AK, Michailidou EZ, Tzimagiorgis G. Salivary markers for oral cancer detection. Open Dent J 2010; 4:172-8.

Received: May 26, 2012

(C) Anastasios K. Markopoulos; Licensee Bentham Open.

This is an open access article licensed under the terms of the Creative Commons Attribution Non-Commercial License (http://creativecommons.org/licenses/by-nc/3.0/) which permits unrestricted, non-commercial use, distribution and reproduction in any medium, provided the work is properly cited. 